\title{
Differential Distribution of Risk Factors and Outcome of Acute Coronary Syndrome in Kuwait: Three Years' Experience
}

\author{
M. Zubaid ${ }^{a}$ C.G. Suresh ${ }^{a} \quad$ L. Thalib $^{b} \quad$ W. Rashed ${ }^{a}$ \\ aDivision of Cardiology, Mubarak Al Kabeer Hospital, and 'bepartment of Community Medicine, \\ Faculty of Medicine, Kuwait University, Kuwait
}

\section{Key Words}

Acute coronary syndrome - Coronary artery disease • Risk factors · Kuwait

\begin{abstract}
Objective: To compare the distribution of risk factors and clinical outcome of acute coronary syndrome (ACS) between Kuwaiti and other Arab men living in Kuwait. Subjects and Methods: The data for this study was collected from the computerized database at the Mubarak AlKabeer Hospital, Kuwait and the 1997-2000 census data for the State of Kuwait. 1,329 Arab men (666 Kuwaitis and 663 other Arabs) older than 25 years who were admitted between September 1997 and August 2000 with a diagnosis of ACS were included in the study. Results: The rate of admission for the entire patient population was twofold higher for Kuwaiti $(1.68 / 1,000)$ than other Arab men $(0.72 / 1,000),(p<0.001)$; the mean age of the Kuwaiti men was $56.7 \pm 11.9$ years and other Arab men $53.0 \pm 10.5$ years $(p<0.001)$. The prevalence of hypertension, diabetes, smoking and hypercholesterolemia for Kuwaiti men was 35.9, 56.9, 51.7 and 36.2\%, respectively; the corresponding prevalence for other Arab men was $28.8,42.7,68.2$ and $32.0 \%$, the difference in the prevalence except for hypercholesterolemia was significant $(p<0.001)$. In Kuwaiti men younger than 55 years of age, the prevalence of hypertension, diabetes
\end{abstract}

\section{KARGER}

Fax +41613061234

E-Mail karger@karger.ch

www.karger.com

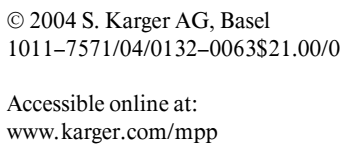

mellitus, smoking and hypercholesterolemia was 26.6, $49.5,68.6$ and $43.3 \%$, respectively; the corresponding values for other Arab men was 22.3, 36.2, 77.7 and 43.3\%; the difference in prevalence except for hypertension was significant $(p<0.001)$. The in-hospital mortality for the whole study was $6.2 \%$ (Kuwaiti) and $2.3 \%$ (other Arab men; $p<0.001)$; while that for men younger than 55 years was $2.7 \%$ (Kuwaiti) and $0.8 \%$ (other Arab men; $p<$ 0.05). Conclusion: The rate of admission for the entire patient population with a diagnosis of ACS was twofold higher for Kuwaiti than other Arab men. Among all patients and also those less than 55 years, the prevalence of diabetes mellitus was consistently higher among Kuwaiti than other Arab men thereby probably leading to the higher admission rate and in-hospital mortality.

Copyright $@ 2004$ S. Karger AG, Basel

\section{Introduction}

Several studies have identified race differences in the rates of coronary artery disease (CAD) and prognosis after acute myocardial infarction (AMI) [1-8]. African-American men have significantly less mortality from CAD than Caucasians [1, 2], whereas Mexican-Americans have a higher mortality than non-Hispanic whites [3, 4]. The overall mortality from AMI among Hispanic women is

Dr. Mohammad Zubaid

Department of Medicine, Faculty of Medicine

PO Box 24923

13110 Safat (Kuwait)

Tel./Fax+965 533 4297, E-Mail zubaid@hsc.kuniv.edu.kw 
Table 1. Rate of ACS by age group among Kuwaiti and other Arab men ( $>25$ years of age)

\begin{tabular}{|c|c|c|c|c|c|c|c|}
\hline \multirow{2}{*}{$\begin{array}{l}\text { Age } \\
\text { group }\end{array}$} & \multicolumn{2}{|l|}{ Population } & \multicolumn{2}{|l|}{$\mathrm{ACS}, \mathrm{n}$} & \multicolumn{2}{|c|}{ ACS rate per 1,000 population } & \multirow[t]{2}{*}{$\mathrm{p}$ value } \\
\hline & Kuwaiti men & other Arab men & Kuwaiti men & other Arab men & Kuwaiti men & other Arab men & \\
\hline $26-29$ & 6,376 & 12,312 & 2 & 4 & 0.31 & 0.33 & NS \\
\hline $30-34$ & 7,256 & 20,331 & 10 & 13 & 1.38 & 0.64 & NS \\
\hline $35-39$ & 6,763 & 17,315 & 38 & 47 & 5.62 & 2.72 & $<0.001$ \\
\hline $40-44$ & 5,784 & 14,369 & 46 & 63 & 7.95 & 4.39 & $<0.005$ \\
\hline $45-49$ & 3,999 & 10,666 & 86 & 124 & 21.51 & 11.63 & $<0.001$ \\
\hline $50-54$ & 3,159 & 7,285 & 111 & 122 & 35.14 & 16.75 & $<0.001$ \\
\hline $55-59$ & 2,374 & 4,535 & 106 & 108 & 44.65 & 23.82 & $<0.001$ \\
\hline $60-64$ & 1,654 & 2,614 & 96 & 86 & 58.04 & 32.90 & $<0.001$ \\
\hline $65-69$ & 1,057 & 1,029 & 70 & 58 & 66.23 & 56.36 & NS \\
\hline $70-74$ & 608 & 424 & 49 & 20 & 80.59 & 47.17 & $<0.05$ \\
\hline $75+$ & 623 & 213 & 52 & 18 & 83.47 & 84.51 & NS \\
\hline Total & 39,653 & 91,093 & 666 & 663 & 1.68 & 0.72 & $<0.001$ \\
\hline
\end{tabular}

significantly lower than that among black or Caucasian women [5]. In several countries, South Asian immigrants have been shown to have an unusually high incidence and mortality from CAD when compared to the other ethnic groups in their adopted country [6-8].

While there has been a significant decline in the incidence of CAD in the industrialized countries, the incidence has been increasing in developing countries [9]. Coronary artery disease has been reported to be the leading cause of mortality in Saudi Arabia, Bahrain and the United Arab Emirates [10-12]. However, there is little comparative data available about the rates of occurrence, risk factors and mortality of CAD among Arabs living in Middle Eastern countries. In this study, we examined the distribution of various risk factors and clinical outcomes for acute coronary syndrome (ACS) between Kuwaiti and other Arab men living in Kuwait.

\section{Subjects and Methods}

The data for this retrospective study were collected from the computerized database of the Coronary Care Unit (CCU), Mubarak AlKabeer Hospital, Kuwait and the 1997-2000 census data for the Hawally Governorate, State of Kuwait. Mubarak Al-Kabeer Hospital is a 476-bed teaching hospital that provides service to almost 450,000 residents in the Hawally Governorate. All patients with ACS were admitted to the CCU. Kuwaiti and other Arab men older than 25 years with a diagnosis of ACS, who were admitted to the CCU between September 1, 1997 and August 31, 2000 and were discharged from or died in the hospital, were included in the study. ACS included patients with AMI and unstable angina. The diagnosis of AMI was based on any two of the following three criteria: ischemictype chest pain, diagnostic serial ECG changes (ST elevation and
non-ST elevation) and twofold rise in total creatinine kinase (CK) with $\mathrm{MB}$ fraction, contributing at least $6 \%$ of the total CK level. A diagnosis of unstable angina was made in patients with typical ischemic chest pain at rest and normal CK levels, with or without ECG changes.

The variables analyzed from the database included detailed information on demographics, medical history, risk factors, admission and discharge diagnosis, and in-hospital mortality. Patients were categorized as Kuwaiti and other Arab men based on nationality. For patients who had more than one admission, data used were from the first CCU admission with a diagnosis of ACS. Hypertension was noted if the patient had a known history of hypertension. Diabetes mellitus was recorded if the patient was a known diabetic on treatment or had a fasting blood sugar $>7.0 \mathrm{mmol} / 1(126 \mathrm{mg} / \mathrm{dl})$ during the hospital admission. Smoking was said to be present if the patient had smoked one or more cigarettes in the last 3 months.

Hypercholesterolemia was said to be present if the patient either was known to have hypercholesterolemia on treatment or had a fasting total cholesterol $>5.5 \mathrm{mmol} / \mathrm{l}(212 \mathrm{mg} / \mathrm{dl})$ within $24 \mathrm{~h}$ of admission.

\section{Statistical Analysis}

Crude rates of admission for ACS among men of different age groups were computed for Kuwaiti and Arab men separately. Variation in the levels of risk factors between the Kuwaiti and other Arab men was assessed using tests of proportion, $\mathrm{Z}$ test for comparing proportion or $t$ tests for comparison of two means. The differences were considered significant on a two-tailed $\mathrm{p}<0.05$. Analyses were carried out using the SPSS program version 10.0.

\section{Results}

\section{Relative Rate of Myocardial Infarction}

During the 1997-2000 census, 39,653 Kuwaiti and 91,093 other Arab men (aggregate average per year) resided in the Hawally Governorate, Kuwait. During this 
Table 2. Comparison of demographics and risk factors between Kuwaiti and other Arab men $>25$ years of age admitted to the $\mathrm{CCU}$ with a diagnosis of ACS

\begin{tabular}{|c|c|c|c|c|c|c|c|}
\hline & \multicolumn{2}{|c|}{$\begin{array}{l}\text { All patients } \\
(\mathrm{n}=1,329)\end{array}$} & \multicolumn{2}{|c|}{$\begin{array}{l}\text { Kuwaiti men } \\
(\mathrm{n}=666)\end{array}$} & \multicolumn{2}{|c|}{$\begin{array}{l}\text { Other Arab men } \\
(\mathrm{n}=663)\end{array}$} & \multirow[t]{2}{*}{$\mathrm{p}$ values } \\
\hline & $\mathrm{n}$ & $\%$ & $\mathrm{n}$ & $\%$ & $\mathrm{n}$ & $\%$ & \\
\hline Hypertension & 430 & 32.3 & 239 & 35.9 & 191 & 28.8 & $<0.01$ \\
\hline Diabetes mellitus & 662 & 49.8 & 379 & 56.9 & 283 & 42.7 & $<0.001$ \\
\hline Smoking & 796 & 59.9 & 344 & 51.7 & 452 & 68.2 & $<0.001$ \\
\hline Hypercholesterolemia & 453 & 34.0 & 241 & 36.2 & 212 & 32.0 & NS \\
\hline AMI & 868 & 65.3 & 401 & 60.2 & 467 & 70.4 & $<0.001$ \\
\hline In-hospital mortality & 56 & 4.2 & 41 & 6.2 & 15 & 2.3 & $<0.001$ \\
\hline
\end{tabular}

\begin{tabular}{|c|c|c|c|c|c|c|c|}
\hline & \multicolumn{2}{|c|}{$\begin{array}{l}\text { All patients } \\
(\mathrm{n}=868)\end{array}$} & \multicolumn{2}{|c|}{$\begin{array}{l}\text { Kuwaiti men } \\
(\mathrm{n}=401)\end{array}$} & \multicolumn{2}{|c|}{$\begin{array}{l}\text { Other Arab men } \\
(\mathrm{n}=467)\end{array}$} & \multirow[t]{2}{*}{$\mathrm{p}$ values } \\
\hline & $\mathrm{n}$ & $\%$ & $\mathrm{n}$ & $\%$ & $\mathrm{n}$ & $\%$ & \\
\hline Hypertension & 247 & 28.5 & 135 & 33.7 & 112 & 24.0 & $<0.01$ \\
\hline Diabetes mellitus & 453 & 52.2 & 243 & 60.6 & 210 & 45.0 & $<0.001$ \\
\hline Smoking & 549 & 63.3 & 217 & 54.1 & 332 & 71.1 & $<0.001$ \\
\hline Hypercholesterolemia & 301 & 34.7 & 144 & 36.0 & 157 & 33.6 & NS \\
\hline In-hospital mortality & 53 & 6.1 & 39 & 9.7 & 14 & 3.0 & $<0.001$ \\
\hline
\end{tabular}

Table 3. Comparison of demographics and risk factors between Kuwaiti and other Arab men $>25$ years admitted to $\mathrm{CCU}$ with AMI period, a total of 1,689 patients of Arab origin were admitted to the CCU with a diagnosis of ACS, of which $1,329(78.7 \%)$ were men. Of these, 666 were Kuwaiti and 663 other Arab men. The crude rate of ACS admission was twice as high among Kuwaiti $(1.68 / 1,000)$ compared with other Arab men $(0.72 / 1000 ; p<0.001)$. The age-specific rates of ACS in each group are given in table 1 . The ACS admission rate was higher in Kuwaitis than other Arab men in the age groups between 35 and 64 years as well as between 70 and 74 years. In younger men less than 34 years and older than 75 years and for those between 60 and 64 years, there was no significant difference in the ACS admission rate.

\section{Risk Factors and In-Hospital Mortality}

The mean age of the study population was $54.9 \pm 11.3$ while that of Kuwaiti and other Arab men was $56.7 \pm$ 11.3 years and $53.0 \pm 11.9$ years, respectively. Risk factor profile and in-hospital mortality for the whole patient population are shown in table 2 . Of the 1,329 patients admitted, 868 had AMI (65.3\%) and 461 unstable angina (34.7\%). AMI occurred in 401 Kuwaiti (60.2\%) and 467 other Arab men $(70.4 \% ; \mathrm{p}<0.001)$. The mean age for the prevalence of hypertension, diabetes, smoking and hypercholesterolemia for Kuwaiti men was 35.9, 56.9, 51.7 and $36.2 \%$, respectively; the corresponding prevalence for other Arab men was 28.8, 42.7, 68.2 and 32\%. The difference in prevalence of hypercholesterolemia between $\mathrm{Ku}-$ waiti and other Arab men was not significant, but that of other risk factors was significant $(\mathrm{p}<0.001)$. In-hospital mortality was $6.2 \%$ among Kuwaiti and $2.3 \%$ among other Arab men $(\mathrm{p}<0.001)$.

Of the 868 patients with AMI, 401 were Kuwaiti and 467 other Arab men (table 3). The mean age was $56 \pm$ 12.1 years and $53 \pm 10.2$ years for Kuwaiti and other Arab men, respectively $(\mathrm{p}<0.001)$. Hypertension, diabetes and hypercholesterolemia were present in 33.7, 60.6 and $36.0 \%$ Kuwaiti men, respectively; corresponding prevalence in other Arab men was 24, 45.0 and $33.6 \%$. Smoking was noted in 54.1 and $71.1 \%$ of Kuwaiti and other Arab men, respectively. Except for hypercholesterolemia, the difference in the risk factors between Kuwaiti and other Arab men was statistically significant $(\mathrm{p}<0.01)$. In-hospital mortality was $9.7 \%$ among Kuwaiti and 3.0\% among other Arab men $(\mathrm{p}<0.001)$.

\section{ACS in Men Less than 55 Years of Age}

The relevant risk factors and in-hospital mortality rate are given in table 4. Of the 669 men, 293 were Kuwaiti and 376 other Arab men; the mean age at presentation was $46.2 \pm 6.1$ years and $45.6 \pm 6.3$ for Kuwaiti and for other Arab men. The difference in age was not statistically 
Table 4. Comparison of demographics and risk factors between Kuwaiti and other Arab men between 25 and 55 years of age admitted to CCU with a diagnosis of AMI

\begin{tabular}{|c|c|c|c|c|c|c|c|}
\hline & \multicolumn{2}{|c|}{$\begin{array}{l}\text { All patients } \\
(\mathrm{n}=669)\end{array}$} & \multicolumn{2}{|c|}{$\begin{array}{l}\text { Kuwaiti men } \\
(\mathrm{n}=293)\end{array}$} & \multicolumn{2}{|c|}{$\begin{array}{l}\text { Other Arab men } \\
(\mathrm{n}=376)\end{array}$} & \multirow[t]{2}{*}{$\mathrm{p}$ values } \\
\hline & $\mathrm{n}$ & $\%$ & $\mathrm{n}$ & $\%$ & $\mathrm{n}$ & $\%$ & \\
\hline Hypertension & 162 & 24.2 & 78 & 26.6 & 84 & 22.3 & NS \\
\hline Diabetes mellitus & 281 & 42 & 145 & 49.5 & 136 & 36.2 & $<0.001$ \\
\hline Smoking & 493 & 73.7 & 201 & 68.6 & 292 & 77.7 & $<0.01$ \\
\hline Hypercholesterolemia & 252 & 37.7 & 127 & 43.3 & 125 & 33.2 & $<0.01$ \\
\hline AMI & 456 & 68.2 & 190 & 64.8 & 266 & 70.7 & NS \\
\hline In-hospital mortality & 11 & 1.6 & 8 & 2.7 & 3 & 0.8 & $<0.05$ \\
\hline
\end{tabular}

significant. Hypertension was present in $26.6 \%$ Kuwaiti and $22.3 \%$ other Arab men (NS). Diabetes mellitus was present in $49.5 \%$ Kuwaiti and $36.2 \%$ other Arab men ( $\mathrm{p}<$ $0.001)$. Smoking was recorded in $68.6 \%$ Kuwaiti and $77.7 \%$ other Arab men $(\mathrm{p}<0.01)$. Hypercholesterolemia was present in $43.3 \%$ of Kuwaiti and $33.2 \%$ of other Arab men $(\mathrm{p}<0.01)$. AMI occurred in $64.8 \%$ Kuwaiti and 70.7\% other Arab men (NS). The in-hospital mortality was $2.7 \%$ among Kuwaiti and $0.8 \%$ among other Arab men $(\mathrm{p}<0.05)$.

\section{Discussion}

This study indicates that the overall admission rate for ACS is higher among Kuwaitis than other Arab men living in Kuwait and is probably due to a higher rate of hypertension and diabetes in Kuwaitis than other Arab men. We have previously reported that Arab men in Kuwait had a higher rate of admission to the CCU compared with South Asian Men [13]. From the present study it appears that this susceptibility for CAD among other Arab men is higher among Kuwaitis compared to other Arab men.

In this study, the prevalence of diabetes mellitus among Kuwaiti men of all ages (56.9\%, table 2 ) and those younger than 55 years $(49.5 \%$, table 4$)$ is much higher than that reported for CAD patients from other studies $[14,15]$. In the Organization to Assess Strategies for Ischemic Syndromes (OASIS) registry [14], among patients with non-ST elevation ACS, the overall prevalence of diabetes mellitus was $21 \%$ with the highest reported among patients from the USA (30\%). Among patients in the US National Registry of Myocardial Infarction-2 [15], the average prevalence of diabetes mellitus was $25 \%$. The very high prevalence of diabetes among Kuwaiti patients has been previously reported in community-based studies
[16-18]. In a population-based cross-sectional study in Kuwait [17], the overall prevalence of type 2 diabetes mellitus among Kuwaiti adults aged $>20$ years was $14.8 \%$. In another study [19], the age-specific prevalence of type 2 diabetes among the Kuwaiti population was $15.4 \%$ in the age group 40-59 years, which increased to $26.3 \%$ in patients above 60 years of age. Studies from Kuwait have also reported a fourfold increase in insulin-dependent diabetes mellitus in children ( $0-14$ years) between the years 1983 and 1993 [17, 18]. The prevalence of diabetes among young Arabs (42\%) is also much higher than that reported from the West $[14,15]$.

The in-hospital mortality rates for the entire patient population for ACS and AMI was higher among Kuwaiti (table 3) than other Arab men. These observations may be explained by the higher number of elderly patients in the Kuwaiti group and also by the higher prevalence of hypertension and diabetes. Another possible explanation is that more of the other Arab than Kuwaiti men possibly died outside the hospital.

Although smoking rate was higher in other Arab men than Kuwaiti men, mortality was found to be lower as reported in previous studies [20, 21]. Substudies of Thrombolysis in Myocardial Infarction trials [21] have shown that despite an increased risk for CAD and AMI, smokers have a paradoxically low mortality from AMI. This has been explained due in large part to lower clinical risk factor profiles and less extensive CAD in smokers. The smoking rate in both Kuwaiti and other Arab men is higher than that reported in the literature $[14,15]$. In the OASIS registry, the rate of smoking was $22 \%$ with the highest in Brazil (27\%) [14]. In the National Registry of Myocardial Infarction-2 [15], the smoking rate was 29\%. In a recent survey from Kuwait [22], the overall prevalence of smoking was $34.4 \%$ in men and $1.9 \%$ in women. While the prevalence of smoking has been reported to be decreasing in the West [23], smoking rates are generally 
believed to be increasing in Kuwait, especially among youngsters [24], posing a potential health problem.

Though Kuwaiti men of all age groups have a higher rate of risk factors compared to other Arab men, the prevalence of these risk factors was unusually high in both groups, compared with rates in Western or developed countries generally $[14,15]$. As a result, the entire resident population of Kuwait is at a high risk of developing not only ACS, but also stroke and peripheral vascular diseases. Since this reality has serious implications on the Kuwaiti health care system, health care authorities should focus aggressively on primary and secondary prevention strategies to limit these risk factors.

\section{Study Limitations}

This study has some inherent limitations. Firstly, the study was confined to men primarily because there were very few other Arab women patients available for inclusion in the study. Other Arab men constitute the main work force in Kuwait and there are only a limited number of other Arab women living in Kuwait. Secondly, as non-Kuwaitis generally return to their homelands on retirement, the remaining other Arab population may be healthier and relatively younger than the Kuwaiti population as evidenced in tables 2 and 3. Thirdly, the characteristics of the admitted patients do not apply to the general population and any conclusions derived from the patient sample to those of the general population may not be accurate. Fourthly, though we believe that almost all patients from the Hawally Governorate, Kuwait were admitted to the Mubarak Al-Kabeer Hospital, some might have been admitted to other hospitals and hence the incidence calculations may not be exact. Lastly, ours is a retrospective analysis, including only a small number of patients. Hence, larger epidemiological studies are required to confirm the findings of in our study.

\section{Conclusion}

The findings indicate that the rate of ACS admission was twofold higher among Kuwaiti men than other Arab men, probably due to higher prevalence of diabetes and hypertension, and that Kuwaiti men presented to the hospital more readily than other Arab men. Prevalence of diabetes mellitus was consistently higher among Kuwaiti than other Arab men. Smoking is prevalent in both groups. A higher in-hospital mortality rate was also seen in Kuwaiti more than other Arab men.

\section{Acknowledgments}

We would like to thank Mrs. Mumtaz Shukoor and Miss Rihab Moneer for their secretarial assistance in the preparation of the manuscript.

\section{References}

1 Keil JE, Sutherland SE, Hames CG, Lackland DT, Gazes PC, Knapp RG, Tyroler HA: Coronary disease mortality and risk factors in black and white men: Results from the combined Charleston, SC, and Evans County, Georgia, heart studies. Arch Intern Med 1995;155: 1521-1527.

2 Gordon HS, Harper DL, Rosenthal GE: Racial variation in predicted and observed in-hospital death: A regional analysis. JAMA 1996;276: 1639-1644.

3 Goff DC Jr, Varas C, Ramsey DJ, Wear ML, Labarthe DR, Nichaman MZ: Mortality after hospitalization for myocardial infarction among Mexican Americans and non-Hispanic white: The Corpus Christi Heart Project. Ethn Dis 1993;3:55-63.

4 Goff DC, Ramsey DJ, Labarthe DR, Nichaman MZ: Greater case-fatality after myocardial infarction in Mexican American women than among non-Hispanic whites and men: The Corpus Christi Heart Project. Am J Epidemiol 1994;139:474-483.
5 Norris SL, deGuzman M, Sobel E, Brooks S, Haywood LJ: Risk factors and mortality among black, Caucasian, and Latina women with acute myocardial infarction. Am Heart J 1993; 126:1312-1319.

6 McKeigue PM, Miller GJ, Marmot MG: Coronary heart disease in south Asians overseas: A review. J Clin Epidemiol 1989;42:597-609.

7 Balarajan R: Ethnic differences in mortality from ischaemic heart disease and cerebrovascular disease in England and Wales. BMJ 1991; 302:560-564.

8 Hughes K, Yeo PP, Lun KC, Thai AC, Sothy SP, Wang KW, Cheah JS, Phoon WO, Lim P: Cardiovascular diseases in Chinese, Malays, and Indians in Singapore: Differences in risk factor levels. J Epidemiol Community Health 1990;44:29-35.

9 Alwan AA: Cardiovascular diseases in the eastern Mediterranean Region. World Health Stat Q 1993;46:97-100.
10 Alballa SR, Bamgboye EA, al-Sekeit M, Alballaa SR: Causes of morbidity among a sample of elderly hospital patients in Riyadh, Saudi Arabia. J Trop Med Hyg 1993;96:157-162.

11 Office of Health Information System: Annual Reports 1982-1990. State of Bahrain, Ministry of Health.

12 Ministry of Health: Annual Report 1992. United Arab Emirates, Ministry of Health, 1994.

13 Suresh CG, Zubaid M, Thalib L, Rashed W, David T: Racial variation in risk factors and occurrence of acute myocardial infarction: Comparison between Arab and South Asian men in Kuwait. Indian Heart J 2002;54:266270.

14 Yusuf S, Flather M, Pogue J, Hunt D, Varigos J, Piegas L, Avezum A, Anderson J, Keltai M, Budaj A, Fox K, Ceremuzynski L: Variation between countries in invasive cardiac procedures and outcomes in patients with suspected unstable angina or myocardial infarction without initial ST elevation. Lancet 1998;352:507514. 
15 Barron HV, Michaels AD, Maynard C, Every NR: Use of angiotensin converting enzyme inhibitors at discharge in patients with acute myocardial infarction in the United States: Data from the National Registry of Myocardia Infarction-2. J Am Coll Cardiol 1998;32:360 367.

16 Abdella N, Al Arouj M, Al Nakhi A, Al Assoussi A, Moussa M: Non-insulin-dependent diabetes in Kuwait: Prevalence rates and associated risk factors. Diabetes Res Clin Pract 1998; 42:187-196.

17 Taha TH, Moussa M, Rashid AR, Fenech FF Diabetes mellitus in Kuwait: Incidence in the first 29 years of life. Diabetologia 1983;25: 306-308.

18 Shaltout AA, Qabazard MA, Abdella NA, LaPorte R, al Arouj M, Ben Nekhi A, Moussa MA, al Khawari MA: High incidence of childhood-onset IDDM in Kuwait: Kuwait Study Group of Diabetes in Childhood. Diabetes Care 1995; 18:923-927.
19 Abdella N, Khogali M, al-Ali S, Gumaa K, Bajaj J: Known type II diabetes mellitus among the Kuwaiti population: A prevalence study. Acta Diabetol 1996;33:145-149.

20 Ottesen MM, Jorgensen S, Kjoller E, Videbaek J, Kober L, Torp-Pedersen C: Age-distribution, risk factors and mortality in smokers and nonsmokers with acute myocardial infarction: A review. TRACE study group. Danish Trandolapril Cardiac Evaluation. J Cardiovasc Risk 1999;6:307-309.

21 Angela BG, Kermgard S, Chen MS, McKay M, Murphy SA, Antman EM, Cannon CP, Braunwald E, Gibson CM: The smokers paradox: Insight from the angiographic studies of the TIMI. J Thromb Thrombolysis 2002;13:133139.
22 Moody PM, Memon A, Sugathan TN, elGerges NS, al-Bustan M: Factors associated with the initiation of smoking by Kuwaiti males. J Subst Abuse 1998;10:375-384.

23 Cooper R, Cutler J, Desvigne-Nickens P, Fortmann SP, Freidman I, Havlik R, Hogelin G, Marler J, McGovern P, Morosco G, Mosca L, Pearson T, Stamler J, Stryer D, Thom T: Trends and disparities in coronary heart disease, stroke and other cardiovascular diseases in United States: Findings from the national conference on cardiovascular disease prevention. Circulation 2000;102:3137-3147.

24 al-Adsani A, Memon A, Peneva A, Baidas G Clinical epidemiology of acute myocardial infarction in Kuwait. Acta Cardiol 2000;55:1723. 